\title{
Article \\ Structure-Property Relationships of Polyamide 12 Grades Exposed to Rapid Crack Extension
}

\author{
Mario Messiha ${ }^{1, *(\mathbb{D}}$, Andreas Frank $^{1}\left(\mathbb{D}\right.$, Jan Heimink $^{2}$, Florian Arbeiter ${ }^{3}\left(\mathbb{D}\right.$ and Gerald Pinter $^{3}(\mathbb{C}$ \\ 1 PCCL GmbH, 8700 Leoben, Austria; andreas.frank@pccl.at \\ 2 Evonik Operations GmbH, 45772 Marl, Germany; jan.heimink@evonik.de \\ 3 Department Polymer Engineering and Science, Montanuniversitaet, 8700 Leoben, Austria; \\ florian.arbeiter@unileoben.ac.at (F.A.); gerald.pinter@unileoben.ac.at (G.P.) \\ * Correspondence: mario.messiha@pccl.at
}

check for updates

Citation: Messiha, M.; Frank, A.; Heimink, J.; Arbeiter, F.; Pinter, G. Structure-Property Relationships of Polyamide 12 Grades Exposed to Rapid Crack Extension. Materials 2021, 14, 5899. https://doi.org/ $10.3390 / \mathrm{ma} 14195899$

Academic Editor: Aleksander Muc

Received: 2 September 2021

Accepted: 4 October 2021

Published: 8 October 2021

Publisher's Note: MDPI stays neutral with regard to jurisdictional claims in published maps and institutional affiliations.

Copyright: (c) 2021 by the authors. Licensee MDPI, Basel, Switzerland. This article is an open access article distributed under the terms and conditions of the Creative Commons Attribution (CC BY) license (https:// creativecommons.org/licenses/by/ $4.0 /)$.

\begin{abstract}
Thermoplastic materials have established a reputation for long-term reliability in lowpressure gas and water distribution pipe systems. However, occasional Slow Crack Growth (SCG) and Rapid Crack Propagation (RCP) failures still occur. SCG may initiate only a small leak, but it has the potential to trigger RCP, which is much rarer but more catastrophic and destructive. RCP can create a long, straight or meandering axial crack path at speeds of up to hundreds of meters per second. It is driven by internal (residual) and external (pressure) loads and resisted by molecular and morphological characteristics of the polymer. The safe installation and operation of a pipe throughout its service lifetime therefore requires knowledge of its resistance to RCP, particularly when using new materials. In this context, the RCP resistance of five different polyamide (PA) 12 grades was investigated using the ISO 13477 Small-Scale Steady State (S4) test. Since these grades differed not only in molecular weight but also in their use of additives (impact modifiers and pigments), structure-property relationships could be deduced from S4 test results. A new method is proposed for correlating these results more efficiently to evaluate each grade using the crack arrest lengths from individual S4 test specimens.
\end{abstract}

Keywords: small-scale steady state (S4) test; rapid crack propagation (RCP); polyamide 12; structureproperty relationships; strain-rate effects

\section{Introduction}

To determine the resistance against Rapid Crack Propagation (RCP) of newly developed plastic pipe grades, the Full-Scale (FS) test, standardized in ISO 13478, has become the "gold standard" for product qualification. It measures a critical pressure value $\left(p_{\mathrm{c}, \mathrm{FS}}\right)$ above which RCP can occur under operating conditions for pressurized pipes in service. However, it requires $25 \mathrm{~m}$ long pipe specimens of up to $500 \mathrm{~mm}$ diameter. Since several FS tests are needed to evaluate the RCP behavior of a given material, this method is expensive and time-consuming.

These disadvantages were mitigated by the development of an accelerated laboratory test, the so-called Small-Scale Steady State (S4) test standardized for thermoplastic pipes in ISO 13477 [1]. The S4 test initiates a rapid crack in a pipe sample only 7 to 8 pipe diameters $(D)$ long. As in the FS test, pipes are tested at a specific temperature (e.g., $0{ }^{\circ} \mathrm{C}$ ) and pressurized with air. RCP is initiated by the impact of a chisel-ended striker close to one end of the pipe. To prevent excess flaring of the pipe walls while allowing the compressed air to escape freely, a rigid cage surrounds the sample, while internal baffles retard axial decompression and ensure a relatively steady pressure in each compartment between them [2].

The result of each $\mathrm{S} 4$ test is classified as propagation if the crack extends to a length $a$ within the gauge section of at least $4.7 D$, or arrest if $0.7 D<a<4.7 D$. Cracks shorter than $70 \%$ of a pipe's diameter are regarded as being too highly influenced by gauge section 
end effects, e.g., insufficient internal gas volume. A series of S4 tests can determine either a critical pressure $\left(p_{\mathrm{c}, \mathrm{S} 4}\right)$ for pipe at a specified temperature or a critical temperature at a specified pressure (Figure 1). In either case, however, false arrest points can appear within the propagation regime (see Figure 1) resulting in a bell-shaped (cloche) crack-length curve and complicating the evaluation of critical pressure or temperature [2].

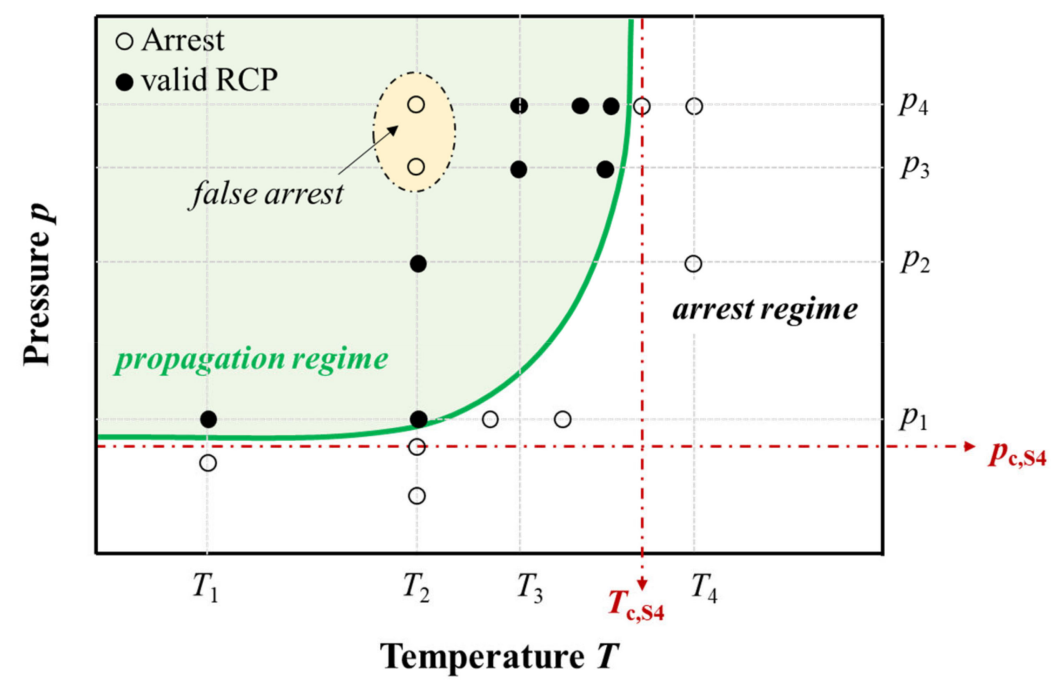

Figure 1. Schematic of crack propagation and arrest regimes for RCP during S4 testing as well as false arrest points within the propagation regime (according to [3]).

The present work developed a more efficient procedure for characterizing the RCP behavior of morphologically different PA12 grades. Various S4 tests were carried out to characterize critical $\mathrm{RCP} /$ crack arrest transition temperatures and pressures, and to more securely establish structure-property relationships. To better understand underlying physical processes, detailed post-mortem examination of fracture surfaces was carried out.

\section{Experimental}

The five PA12 grades selected for this study (Figure 2) were part of a systematic series of unplasticized grades that differed primarily in their molecular weight $\left(M_{\mathrm{W}}\right)$ and/or the use of specific additives, such as an impact modifier (IM) or an inorganic pigment (PGM). Four of the five grades, coded with the letter " $\mathrm{C}$ ", are highly viscous compounds based on PA12-0 (Figure 2). C3-nc is a natural colored (nc) compound without impact modification. Adding an IM to it yields C4-im-nc, while additional coloration results in C2-im-pgm. Finally, C5-im-pgm can be viewed as a derivative of C2-im-pgm, modified to increase molecular weight.

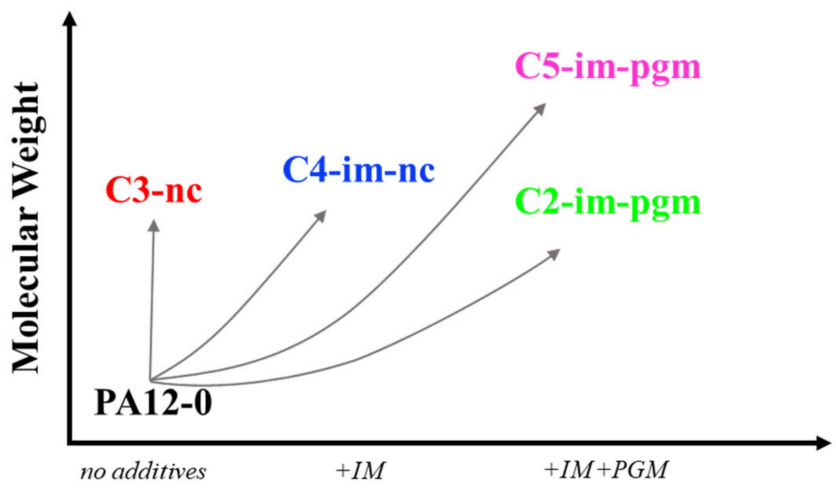

Additives

Figure 2. Systematically developed series of unplasticized PA12 grades. 
Weight average molecular mass $M_{\mathrm{w}}$ was measured using Size Exclusion Chromatography (SEC). Samples taken from extruded pipes of the given materials were dissolved in hexafluoroisopropanol (HFIP) and potassium-trifluoroacetate at room temperature. Table 1 summarizes relevant properties of the selected materials; for clarity, $M_{\mathrm{w}}$ values are normalized against that of PA12-0.

Table 1. Basic characterization of selected PA12 grades.

\begin{tabular}{lccc}
\hline \multicolumn{1}{c}{ Material } & IM & PGM & $M_{\text {W,rel }}$ \\
\hline PA12-0 & - & - & 1.0 \\
C2-im-pgm & + & + & 1.2 \\
C3-nc & - & - & 1.4 \\
C4-im-nc & + & - & 1.5 \\
C5-im-pgm & + & + & 1.6 \\
\hline
\end{tabular}

Each grade was first characterized for RCP resistance using the S4 test according ISO 13477 [1]. Extruded pipe specimens with a length of $835 \mathrm{~mm}$, an outer diameter of $D=110 \mathrm{~mm}$ and a Standard Dimension Ratio (SDR) 11 were used. Applied pressures ranged from 1.5 bar to 8 bar at temperatures between $0{ }^{\circ} \mathrm{C}$ and $45^{\circ} \mathrm{C}$ and the impact speed was $16 \mathrm{~m} / \mathrm{s}$. Furthermore, a newly modified data evaluation process, which additionally accounts for the crack length $a$ in relation to the to the maximum possible crack length ( $\left.a_{\max }\right)$ of $758 \mathrm{~mm}$ (i.e., from the center of the impact position to the end of the gauge length), is suggested. Fracture surfaces were studied using a Tescan Vega II Scanning Electron Microscope (Tescan Brno, Brno, Czech Republic).

\section{Results and Discussion}

Critical pressure results for the five PA12 grades are shown in Figure 3. Solid symbols represent tests with valid RCP initiation according to ISO 13477 [1], while hollow symbols represent valid RCP arrests. At $T=0^{\circ} \mathrm{C}$, the grades can be grouped as follows:

1. Those with low critical pressures of $\sim 3.2$ bar: these include neat PA12-0 as well as C2-im-pgm;

2. Those with slightly higher $p_{\mathrm{c}, 0{ }^{\circ} \mathrm{C}}$ values of 4.1-4.4 bar: C4-im-nc and C5-im-pgm; and 3. C3-nc, having the remarkably high $p_{\mathrm{c}, 0^{\circ} \mathrm{C}}$ of $\sim 8$ bar.

At temperatures above $20^{\circ} \mathrm{C}$ the critical RCP pressure increases significantly for all materials tested. Only PA12-0 still exhibited valid RCP at $T>25^{\circ} \mathrm{C}$ and pressures of up to 12 bar, with no crack arrest seen even at $45^{\circ} \mathrm{C}$-which exceeds the $T_{\mathrm{g}}\left(40^{\circ} \mathrm{C}\right)$. This indicates a very high critical S4 temperature $T_{\mathrm{c}, \mathrm{S} 4}$ and very poor RCP resistance. Compounded grades, on the other hand, exhibit $T_{\mathrm{c}, S 4}$ values of around ambient temperature.

The chain lines shown for each material in Figure 3 sketch boundaries between RCP arrest and propagation regions. However, there are not enough data points to identify for every material, with adequate precision, either an ISO 13477 [1] critical pressure at a given temperature (e.g., C3-nc at $T=0{ }^{\circ} \mathrm{C}$ ) or a critical temperature at a given pressure (e.g., PA12-0 and C5-im-pgm at $p=12$ bar). To do so, as Figure 2 illustrates schematically for just one material, a significant number of additional tests would be needed.

To maximize the data yield from each test the measured arrest length of each crack was processed numerically, as well as being classified as arrest/propagation (see Figures 4 and 5). Plotting at least three crack lengths as a function of test pressure at a given temperature (e.g., at $0{ }^{\circ} \mathrm{C}$, Figure 4 ) allows the critical pressure to be extrapolated by linear regression. For example, instead of starting at extreme pressures and successively decreasing the applied $p$ at a constant $T$ to obtain the point of transition from RCP to crack arrest, it is proposed to test first at very low $p$ and then at very high $p$. The critical S4 pressure point can then be estimated by intra- or extrapolation and refined successively by additional intermediate tests. If possible, it is recommended to base the linear regression primarily on data points between $0.7 D<a<4.7 D$, in order to avoid effects from initiation as well as reflection of decompression waves and end-cap constraints. 


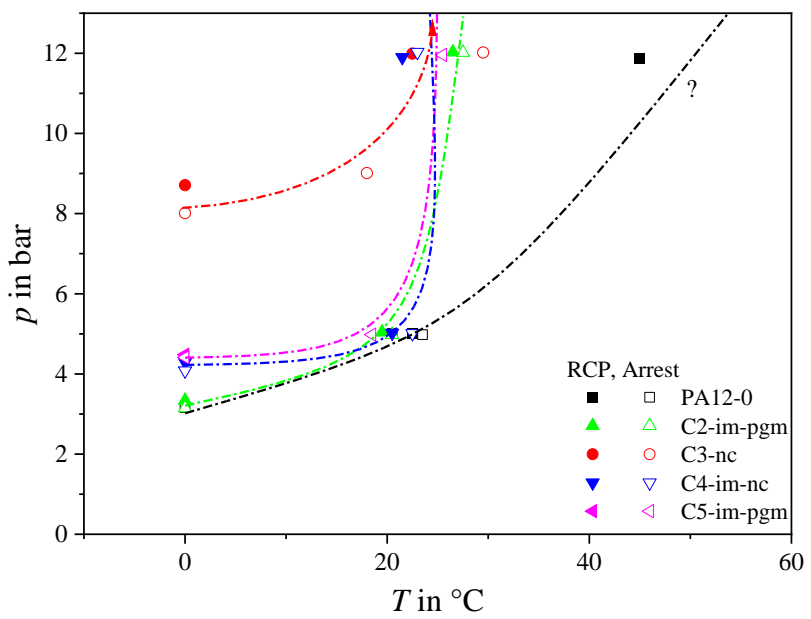

Figure 3. RCP characteristics of various PA12 grades measured via S4 tests.

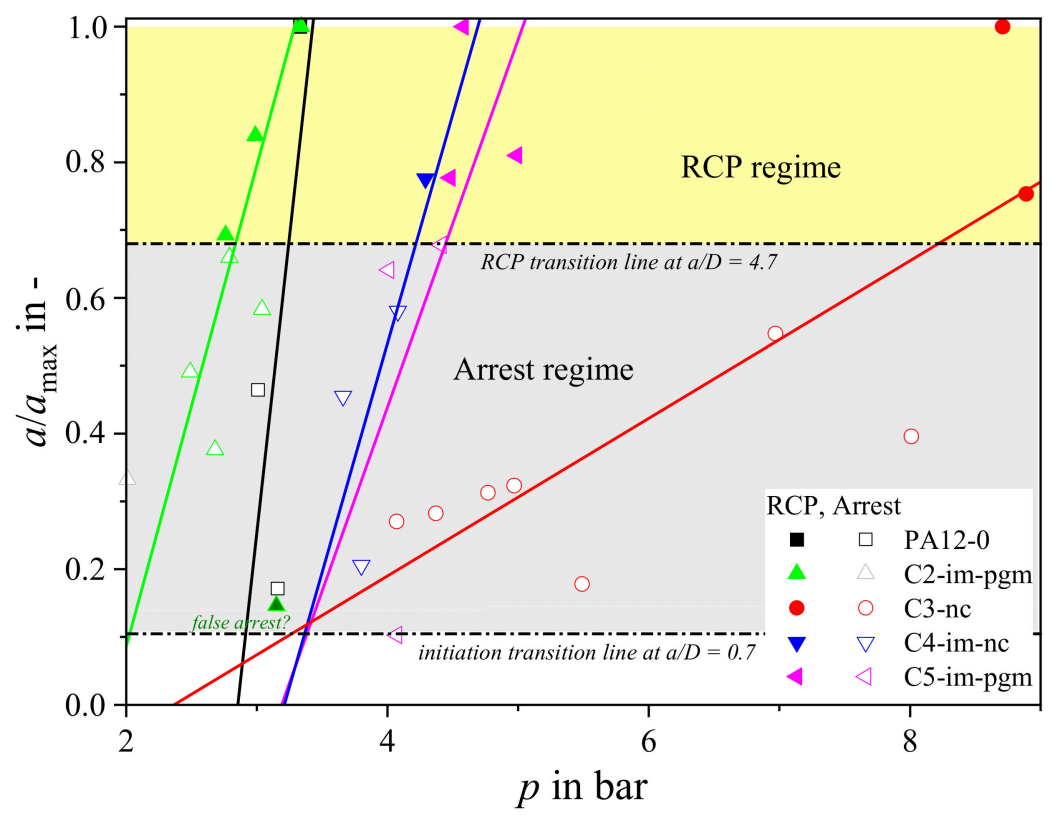

Figure 4. Modified evaluation of the critical pressure values of all grades at $0{ }^{\circ} \mathrm{C}$. 


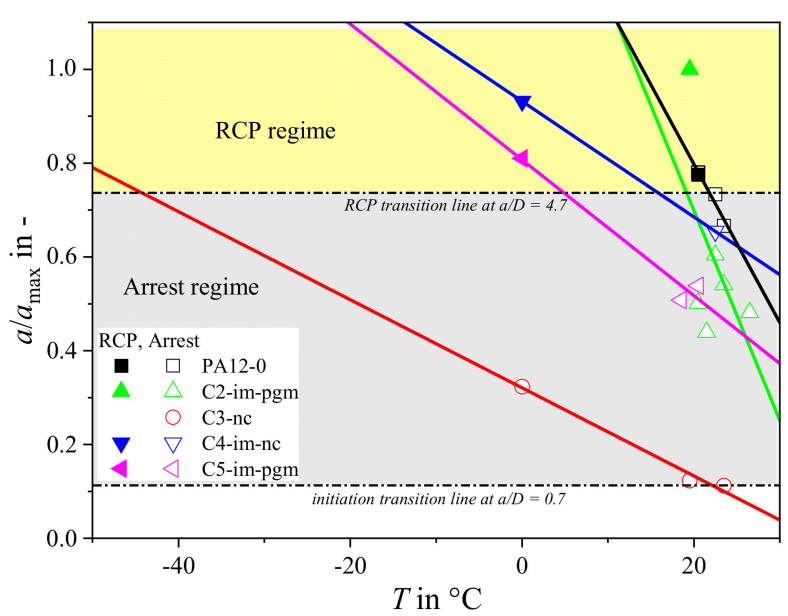

(a)

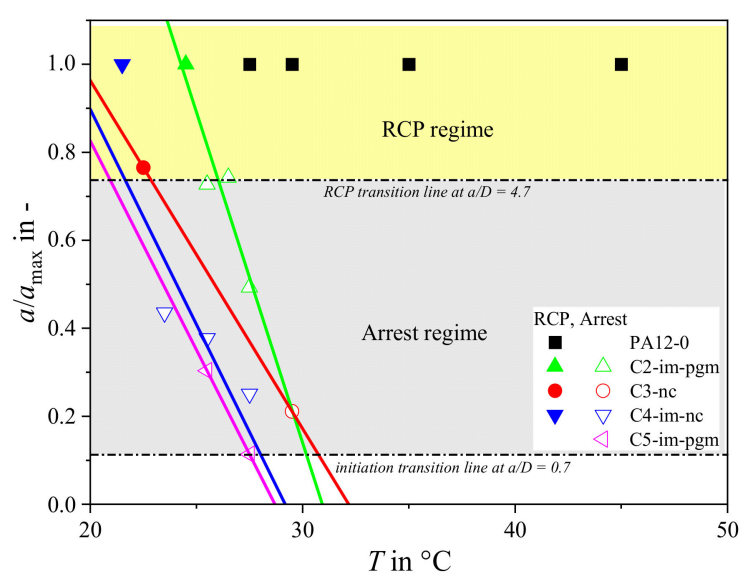

(b)

Figure 5. Modified evaluation of the critical temperature values of all grades at (a) 5 bar and (b) 12 bar.

Using this method yielded slightly different $p_{\mathrm{c}, 0^{\circ} \mathrm{C}}, T_{\mathrm{c}, 5 \mathrm{bar}}$, and $T_{\mathrm{c}, 12 \mathrm{bar}}$ values (Figures 5 and 6) from those using the ISO standard method. Each grade except PA12-0 could be characterized at $0{ }^{\circ} \mathrm{C}, 5 \mathrm{bar}$, and 12 bar (Figure 5b). The use of crack length data also makes it easier to exclude false arrest points that might significantly affect the critical pressure result (e.g., C2-im-pgm in Figure 4).

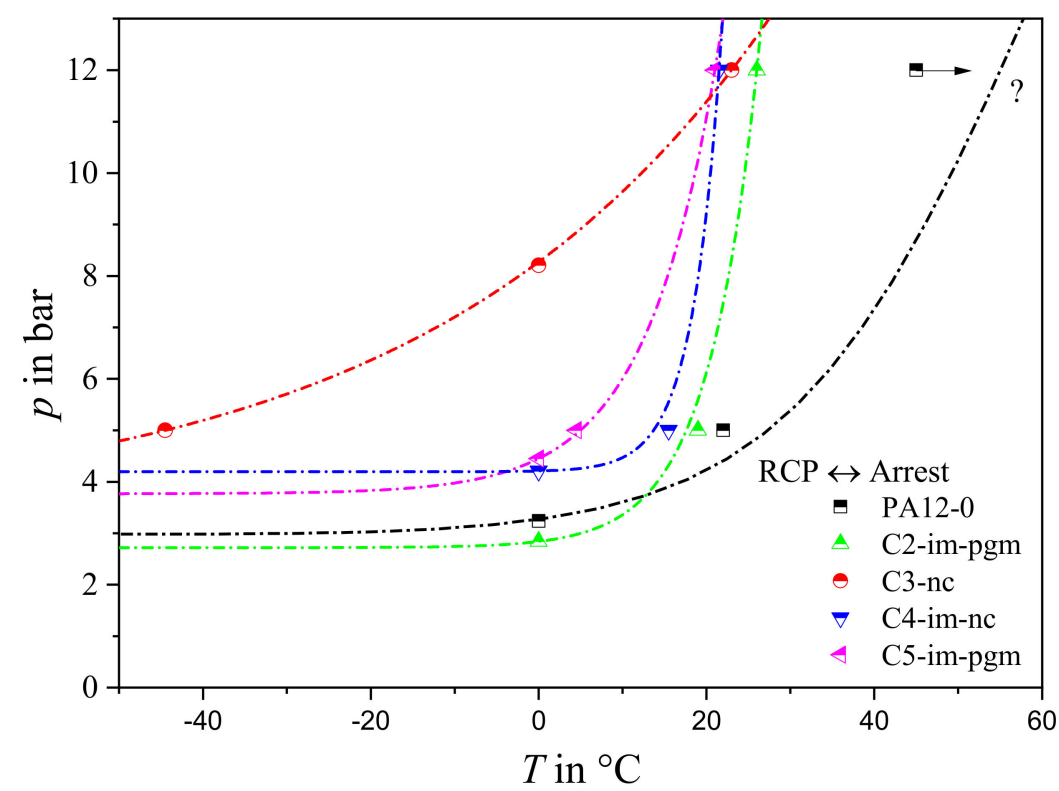

Figure 6. Rapid fracture behavior of PA12 grades as acquired from S4 tests according to the modified evaluation with predicted $\mathrm{RCP} /$ crack arrest transition points.

Table 2 compares transition values obtained using this method with those from the ISO standard procedure. Clearly the same amount of $\mathrm{S} 4$ test data can now yield more $T_{\mathrm{c}, 5 \mathrm{bar}}$ and $T_{\mathrm{c}, 12 \mathrm{bar}}$ values. 
Table 2. Standard evaluation according ISO 13477 vs. modified evaluation of S4 test data.

\begin{tabular}{|c|c|c|c|c|c|c|}
\hline \multirow[b]{2}{*}{ Material } & \multicolumn{3}{|c|}{ ISO 13477} & \multicolumn{3}{|c|}{ Modified S4 Evaluation } \\
\hline & $\begin{array}{l}p_{c, 0^{\circ} \mathrm{C}} \\
\text { (bar) }\end{array}$ & $\begin{array}{c}T_{c, 5 b a r} \\
\left({ }^{\circ} \mathrm{C}\right)\end{array}$ & $\begin{array}{c}T_{\mathrm{c}, 12 \mathrm{bar}} \\
\left({ }^{\circ} \mathrm{C}\right)\end{array}$ & $\begin{array}{l}p_{\mathrm{c}, \mathrm{O}^{\circ} \mathrm{C}} \\
\text { (bar) }\end{array}$ & $\begin{array}{c}T_{c, 5 b a r} \\
\left({ }^{\circ} \mathrm{C}\right)\end{array}$ & $\begin{array}{c}T_{c, 12 \mathrm{bar}} \\
\left({ }^{\circ} \mathrm{C}\right)\end{array}$ \\
\hline PA12-0 & 3.16 & 22.5 & $*$ & 3.24 & 22 & \\
\hline C2-im-pgm & 3.15 & 20.5 & 27.5 & 2.84 & 19 & 26 \\
\hline C3-nc & 8.01 & $*$ & $22-29.5$ & 8.21 & -44.5 & 23 \\
\hline C4-im-nc & 4.08 & 22.5 & 23 & 4.22 & 15.5 & 21.5 \\
\hline C5-im-pgm & 4.41 & $*$ & $*$ & 4.45 & 4.5 & 21 \\
\hline
\end{tabular}

* No RCP/crack arrest transition detectable at given pressure or temperature levels.

Transition temperatures extrapolated using crack length measurements are plotted in Figure 6. Except for PA12-0-having only two transition point data-transition lines were determined via exponential fitting, allowing standard S4 failure lines to be extended beyond the test data envelope (e.g., $T_{\mathrm{c}, 5 \mathrm{bar}}$ of C3-nc). The two evaluation methods yield very similar results (cf. Figures 3 and 6) showing that PA12-0 and C2-im-pgm fall short of the remaining compounds, becoming susceptible to RCP at lower applied pressures. While C2-im-pgm becomes resistant to RCP above ambient temperature, PA12-0 remains susceptible over a wider temperature range. In contrast, C3-nc exhibits an extraordinary RCP resistance. At $T=0{ }^{\circ} \mathrm{C}, \mathrm{RCP}$ only occurs at much higher pressures than in the other grades. This implies that significantly increasing $M_{\mathrm{W}}$ by compounding (e.g., from PA12-0 to C3-nc, Figure 2) benefits RCP resistance. Krishnaswamy et al. [4] and Argyrakis [3] reported similar observations for PE-HD: high molecular weight and narrow molecular weight distributions appear to be important to superior RCP resistances in PE-HD.

In contrast, comparing C3-nc and C4-im-nc indicates that impact modifier has a negative effect on RCP resistance. Rubbers are widely used to toughen polymers in critical applications that might expose them to impact loads. In theory, the soft particles absorb much of the input impact energy, either by stretching the rubbery material, or by promoting multiple crazing, shear yielding or the combination of both [5]. The contribution of each mechanism to toughen the rubber-matrix system depends on a number of variables, such as the rubber particle size, distribution and concentration [6]. However:

(1) Impact modifiers generally increase the initiation resistance $G_{\text {Ic }}(t)$ to rapid loading of a crack but do not influence resistance to its propagation [7-10];

(2) Impact modifiers are themselves time-dependent elastomers undergoing significant strain-rate hardening $[5,10,11]$.

It can, therefore, be assumed that rubber particles have enough time during static and quasi-static load conditions (i.e., low and moderate local strain rates) to plastically deform and cavitate, enhancing the resistance to (quasi-) static crack initiation $G_{\text {Ic }}$ through extensive shear yielding or multiple crazing phenomena. If the applied (quasi-) static crack driving force $G$ reaches the critical $G_{\mathrm{Ic}}$ a crack starts to extend at low crack speeds $\dot{a}$. Thereby, low crack opening strain rates prevail at areas surrounding the crack tip, so that incorporated elastomers get easily strained and continue to absorb large amounts of energy even during slow crack extension [5]. In contrast, a structure exposed to highly dynamic, time-dependent load conditions $G(t)$ experiences local deformations at extremely high rates. Once $G(t)$ becomes equal to or bigger than the time-dependent initiation fracture toughness $G_{\mathrm{Ic}}(t)$ of a rate-sensitive material, a rapid crack is initiated. In that context, time $t$ is substitutable with the applied impact speed $v$ during an abrupt loading. Considering Figure 7, it becomes clear why an improvement of fracture initiation properties due to rubber toughening of rate-sensitive plastics is ineffective at very high impact speeds (e.g., $\mathrm{S} 4$ tests). As $G_{\mathrm{Ic}}(v)$ is possibly reduced to a minimum value [12], the fundamental rapid fracture resistance of different pipe grades during $\mathrm{S} 4$ testing at $16 \mathrm{~m} / \mathrm{s}$ load speed can be considered to be primarily dependent on the dynamic crack propagation resistance $G_{\mathrm{Id}}(\dot{a})$ after crack initiation. 


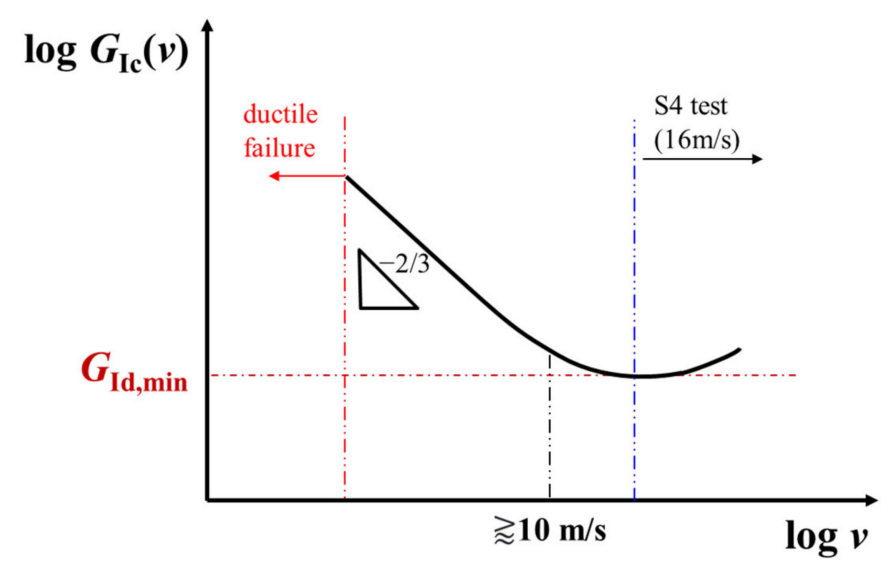

Figure 7. Schematic illustration of a time-dependent initiation energy release rate $G_{\mathrm{Ic}}(v)$ as a function of the load rate $v$ for rate-sensitive materials with dominating embrittlement (in accordance to [13]).

Subsequently, the soft rubber parts of the microstructure at the vicinity of the fastrunning crack tip have no time to follow the governing local crack opening deformations. Even worse, bearing the time-temperature principle in mind, it may be well suggested that elastomeric parts could pass through the glass transition when a critical local strain rate is exceeded, which is equivalent to the rubber's $T_{\mathrm{g}}$ or tough-brittle transition temperature $\left(T_{\mathrm{TB}}\right)$. In that case, the hardened rubber particles might act as additional stress concentrators, at which rapid cracks initiate and propagate more easily. As a result, the incorporation of tougheners may feature a significant reduction of the RCP resistance during S4 testing [10]. This hypothesis is validated by the S4 results of C3-nc and C4-im-nc, where the systematic addition of an IM leads to remarkably lower critical $p_{\mathrm{c}, S 4}$ values (Figure 6).

On the same basis, the pigmentation of materials exposed to crack driving forces can correspond to the addition of inherent defects and localities of stress concentrations at which cracks are preferentially launched. Several studies confirm that the improvement of esthetical properties of different materials by coloration is often accompanied by significant reductions of their fracture toughness [14-17]. In that manner, the addition of an inorganic pigment to C4-im-nc resulting in C2-im-pgm, yields to a further decrease of $p_{\mathrm{c}, S 4}$ from approximately 4.2 to $3.2 \mathrm{bar}$ (or even less, if false arrests are accounted for). Simultaneously, the critical $T_{\mathrm{c}, S 4}$ is slightly shifted towards higher values-from $23{ }^{\circ} \mathrm{C}$ to $27.5^{\circ} \mathrm{C}$ - which further affirms the rather negative impact of coloration on rapid fracture behavior. Finally, C5-im-pgm, which equals a high-molecular weight $\mathrm{C} 2$-im-pgm, achieves improved $p_{\mathrm{c}, S 4}$ values of $4.5 \mathrm{bar}$ and slightly lower $T_{\mathrm{c}, S 4}$ values of $25^{\circ} \mathrm{C}$. This corresponds to the counterbalancing effect of an enhanced $M_{\mathrm{W}}$ on a material's RCP resistance.

Studying the overall shape of the S4 failure regimes presented in Figure 6 it can also be seen that both grades, which do not contain a rubber part, exhibit a successive increase of RCP resistance with rising temperatures. In contrast, the three impact modified grades hardly show any kind of improvement in terms of RCP resistance with increasing temperatures up to $0{ }^{\circ} \mathrm{C}$. However, once a critical temperature around $10-20{ }^{\circ} \mathrm{C}$ is reached, the impact modifier seems to go through a brittle-tough transition at underlying strain rates and quickly transfers from an inherent defect to an energy absorber, explaining the rather sharp transition observed in S4 results of C2-im-pgm, C4-im-nc, and C5-im-pgm.

Fracture surfaces of S4 tested PA12 samples are presented in Table 3. Macroscopic overview images of all grades (Table 3a) reveal a major difference between the general fracture appearance of non-toughened and toughened grades. Basically, non-toughened grades PA12-0 and C3-nc exhibit a very rough surface, with structural discrepancies. Contrarily, PA12 grades with integrated soft particles present smoother fracture surfaces. Furthermore, a distinction between two noticeable microscopic structures can be made for all grades: regions of distinctive river lines that look like deep carvings inside the fractured surfaces (Table $3 b$ ), as well as a dominating flat failure region (often denoted as mirror zone [18]), which appears featureless at low magnification images (Table 3c). At this mirror 
zone intense crack acceleration might be expected, regardless of the imposed load rate. Although river lines are commonly observed on RCP fracture surfaces [3,19], no universal theory could be found, describing how this river pattern of radiating lines is caused. Basically, river lines are believed to originate from the interconnection of micro-cracks at different fracture surface levels of cleavage plains with different orientations with the main fracture plane [20]. Hayes et al. [21] observed river markings to be more pronounced if polymers experience a mixed mode loading, in particular Mode I and Mode III. As the main crack moves across the component, micro-cracks coming from different cleavage planes have to rotate to keep the continuity of RCP. Thus, river markings are dependent on the micro-structure of the material and become significantly prominent with increasing Mode III $[20,21]$. From Table $3 \mathrm{~b}$ it can be seen, that river lines also vary on a microstructural scale. Particularly, C4-im-nc and C5-im-pgm display a spherulite-like marking of different sizes around river lines, which may be provoked by either the incorporated IM or pigment. Surprisingly, the structure of C2-im-pgm is quite similar to that of C3-nc, which does not contain IM or pigments. A magnified view on the featureless fracture region (compare Table $3 a-c)$ reveals a reversed tendency with regard to aforementioned macroscopic fracture appearances. In that context, PA12 grades that contain an impact modifier highlight a very coarse surface with many irregularities and bumps, especially in combination with color pigments (i.e., C2-im-pgm and C5-im-pgm), whereas PA12-0 and C3-nc are relatively smooth in comparison.

In order to analyze the aforementioned river lines more deeply, the scanning electron beam used during SEM measurements was angled about $45^{\circ}-52^{\circ}$ to fracture surface. In doing so, it became possible to take a closer look underneath river markings on RCP fracture surfaces. An evident fibrillation was found beneath each observed river line in almost all grades-an example of C2-im-pgm is given in Figure 8a. Principally, there are two major views, advocated in the scientific community, with regard to the actual failure mechanism during rapid fracture events. The first perspective considers chain scission of covalent backbone bonds as dominant failure mechanism as reported by Donald and Kramer [22,23], Plummer and Kausch [24], as well as Deblieck [25]. This position is based on the fact that the crack speed is too high to promote chain reptation and subsequent disentanglement. The second viewpoint, however, considers chain disentanglement to be still the dominant mechanism, as it is the case for slow crack growth (SCG) [22,23,26-29]. In contrast to SCG, however, which is guided by mechanical creep and chain slipping against secondary forces (e.g., van der Waal, hydrogen bonds, etc.) of neighboring chains, chain disentanglement is assumed to be promoted by additional adiabatic heating processes [12,30-32] during fast fractures. The idea of a thermal decohesion mechanism during RCP assumes that adiabatic conditions are certainly obtained at high crack speeds due to the low thermal conductivity of polymers. This was reported by Leevers [12] for PE-HD, but also for brittle bulk metallic glass that exhibited a maximum crack velocity of $\sim 800 \mathrm{~m} / \mathrm{s}$ [33]. Considering Figure $8 \mathrm{a}$, such fibrillated structures seem to be highly improbable, if RCP is solely governed by chains scission. Yet, an adiabatic decohesion mechanism [12,30,32], would predict thermo-mechanically activated fibrillation and cavitation. In agreement with aforementioned fundamental observations of river markings, a conceivable explanation for river lines in PA12 could be that they were regions of rapidly extending crack fronts, which eventually stopped at an instance of time, before jumping into a neighboring crack plane (Figure 8b). Reason therefore could be the superposition of different reflected stress waves at the crack tip, varying stress triaxiality levels along the thickness of the pipe, as well as inhomogenously distributed weak points (e.g., crystal defects, contaminations, pigments or hardened impact modifiers). Only if adiabatic decohesion is governing RCP on a molecular level, the abrupt change of the main crack plane would leave behind a ridge of fibrillar structures, that is not able to continue participating in the physical crack extension by thermal decohesion $[12,30,32]$. With a new hot craze-crack front passing by in a "new" main crack plane, fibrils beneath river lines solidify, freezing in the observed structures in Figure 8a. 
Table 3. Fracture surface analysis of S4 tested PA12 pipe fragments via SEM: macroscopic overview (a), river line regions (b) and brittle rapid fracture regions (c).
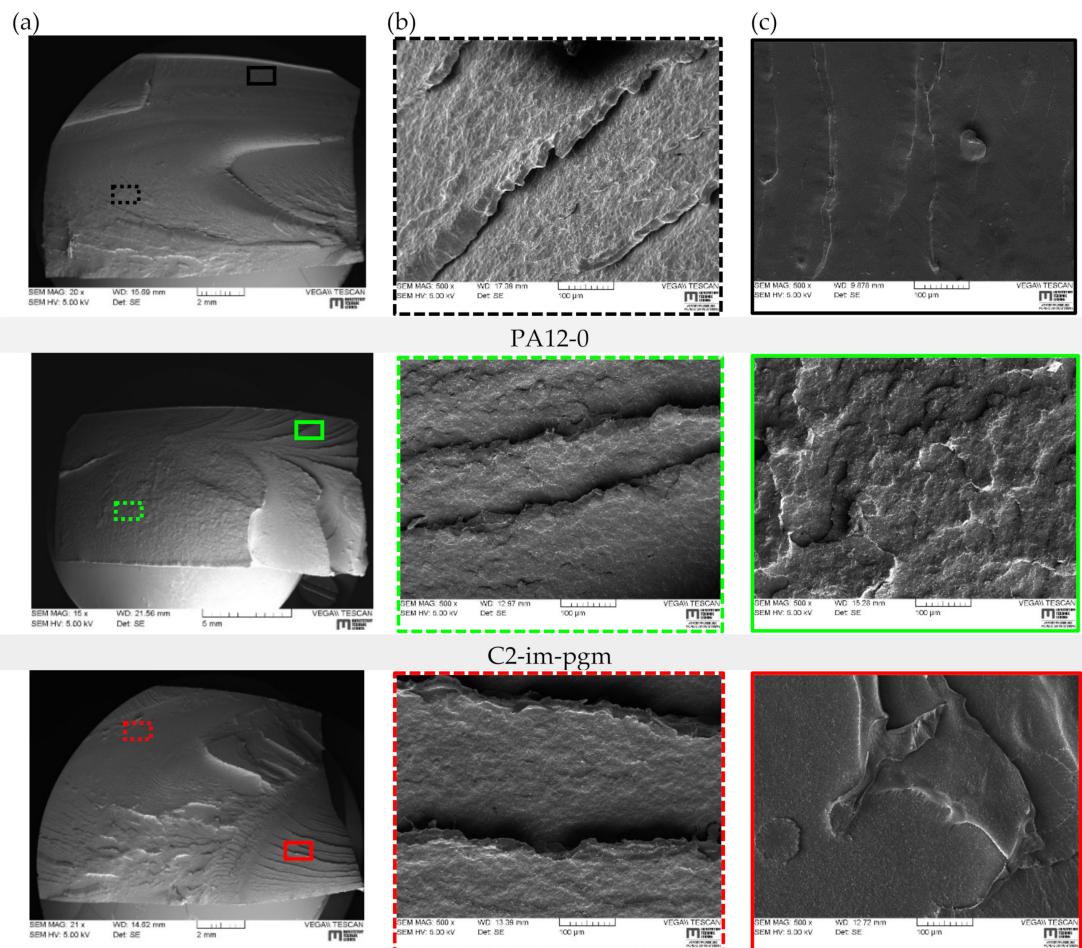

C2-im-pgm
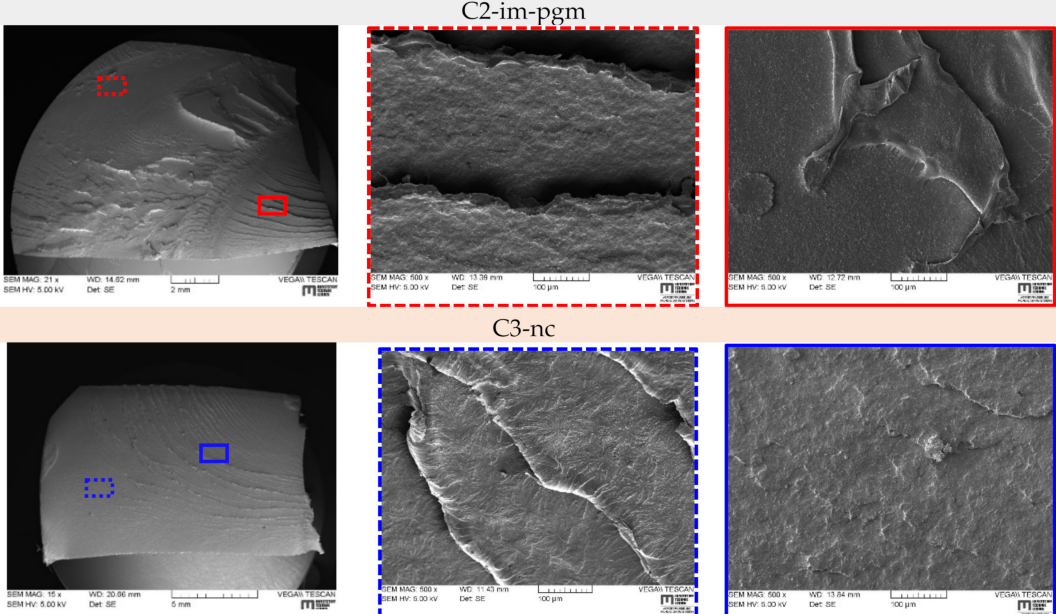

C3-nc
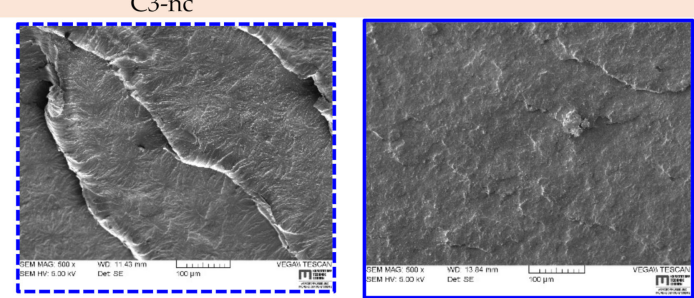

C4-im-nc
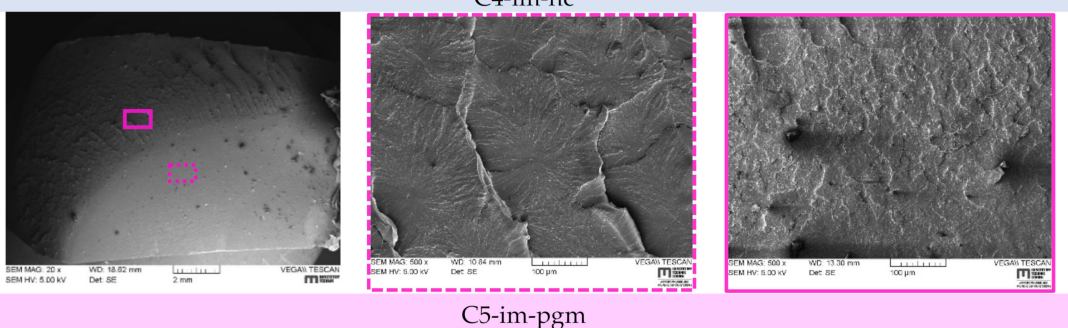

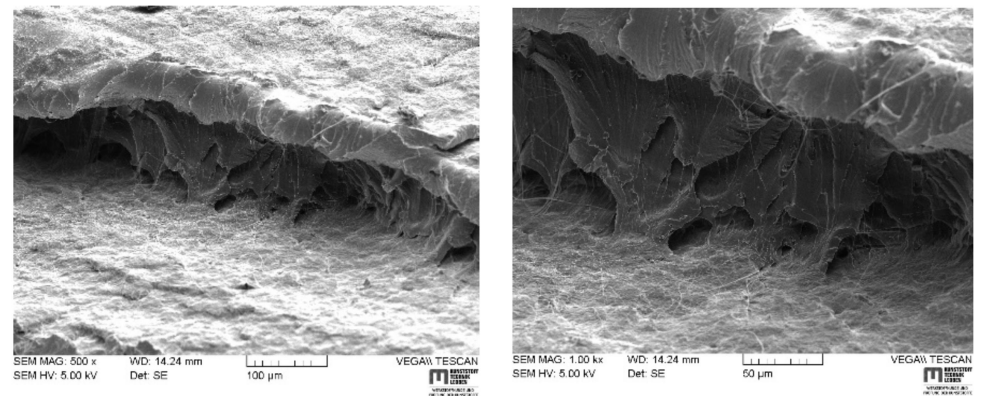

(a)

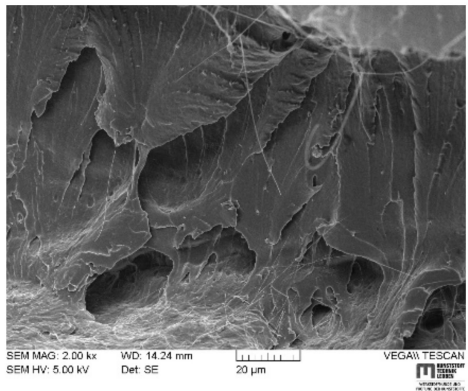

nim:

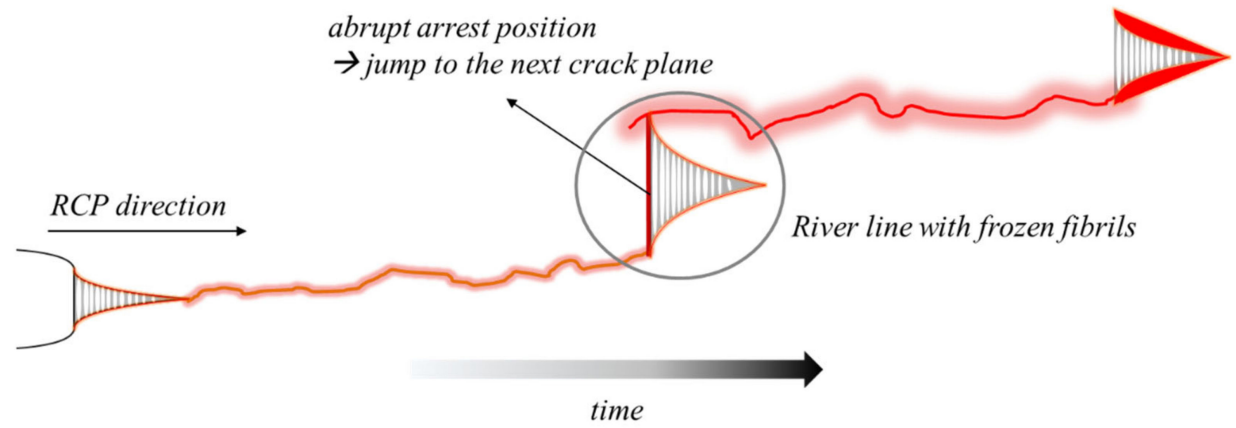

(b)

Figure 8. Fibrillar structures beneath river lines with increasing magnification (a) and schematic representation of how these structures could have evolved (b).

Another feature indicating the presence of high temperature localities during RCP might be seen in uniform-width, almost-straight lines fibrillar structures that could be observed on the high-magnification images of most PA12 grades (Figure 9). The length of this thin fibrils deviates from nano-meter to micro-meter scale, whereas the thickness remains essentially constant (about a few hundred nano-meters). At the current stage it is not clear how these structures were built and why they did not collapse back into the melt layer, if an adiabatic decohesion mechanism is true for RCP fractured PA12 grades (e.g., as thermoplastic fibers would do in the hot air stream from a hair-dryer). However, it is clear, that huge amounts of thermal energy are necessary to drain these very thin structures from a craze zone or the bulk during fracture. Additionally, perhaps if they were thicker they would contract back to the melt zone, because they would retain heat for long enough to do so, yet, due to their very thin nature solidification may occur very fast [34].
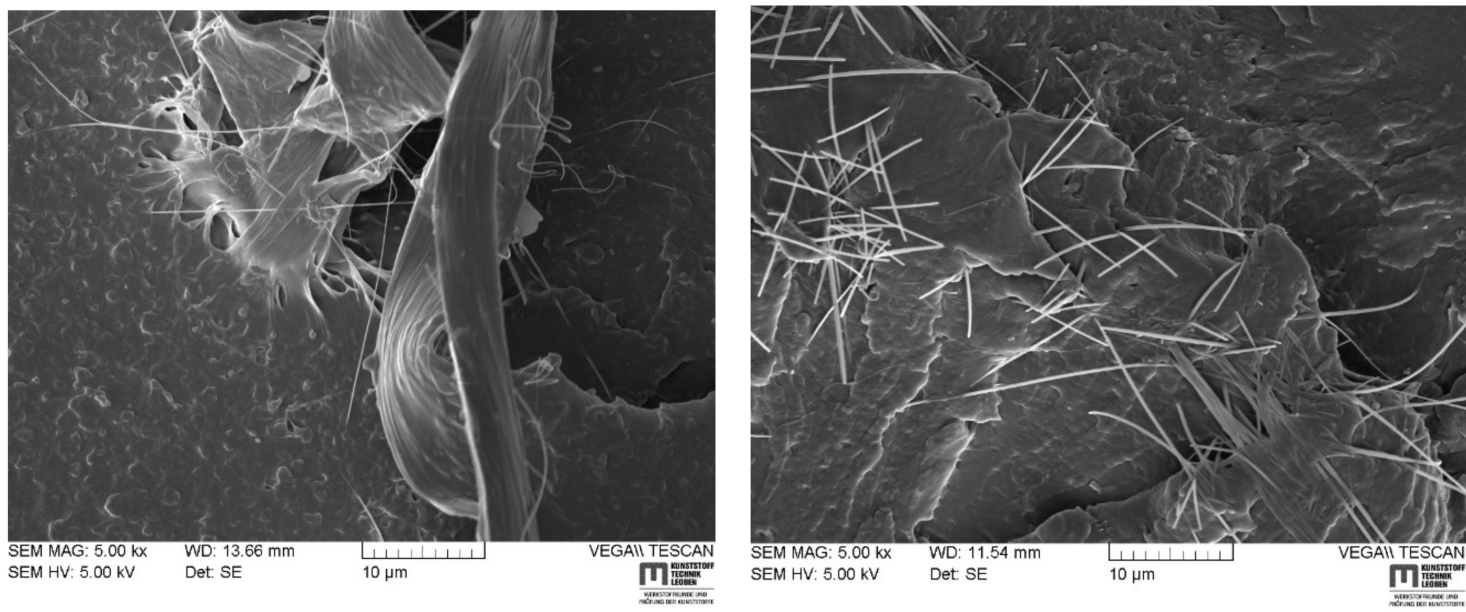

Figure 9. Characteristic macro-(left) and micro-fibrillar (right) structures found in all PA12 grades along the crack path after rapid fracture. 


\section{Conclusions and Outlook}

This study has highlighted relevant structure-property relationships regarding the resistance against Rapid Crack Propagation (RCP) in morphologically different polyamide (PA) 12 grades. The RCP performance was measured using the Small-Scale Steady State (S4) test according to ISO 13477. An obvious improvement of the RCP resistance was observed with increasing molecular weight $M_{\mathrm{W}}$, while the incorporation of inorganic pigments reduced the rapid fracture toughness of PA12. Furthermore, rubber-toughening of PA12 grades was also found to decrease the RCP resistance, due to underlying strain-rate effects. In contrast to the general believe that chain scission mechanism is governing physical processes on a molecular scale during $\mathrm{RCP}$, fractographic analysis of S4 fractured pipe samples indicate the existence of high temperature, probably due to adiabatic conditions. In this regard the present work may be viewed as the first step to explain the complex relationship between rapid fracture performances of PA12 grades and underlying fracture mechanisms, such as thermo-mechanical chain disentanglement by means of adiabatic decohesion. Another key element of this research was the proposal of a novel evaluation concept of the S4 test results to improve the determination of critical temperature and pressure values on the basis of a significantly reduced amount of $S 4$ tests.

Author Contributions: M.M.: Conceptualization, Methodology, Investigation, Data curation, Writing-original draft, Project administration. A.F.: Supervision, Writing-review \& editing. J.H.: Resources, Funding acquisition, Writing-review \& editing. F.A.: Supervision, Writing-review \& editing. G.P.: Supervision, Writing — review \& editing. All authors have read and agreed to the published version of the manuscript.

Funding: This research was funded by the Austrian Government and the State Governments of Styria and Upper Austria within the framework of the COMET-program of the Federal Ministry for Transport, Innovation and Technology (Austria) and Federal Ministry for Economy, Family and Youth (Austria).

Acknowledgments: Research work of this paper was performed at the Polymer Competence Center Leoben $\mathrm{GmbH}$ (PCCL, Austria) with contributions by Evonik Operations GmbH (Germany) and the Montanuniversitaet Leoben (Austria).

Conflicts of Interest: The authors declare no conflict of interest.

\section{References}

1. International Standards Organisation (ISO). Thermoplastics Pipes for the Conveyance of Fluids-Determination of Resistance to Rapid Crack Propagation (RCP)—Small-Scale Steady-State Test (S4 Test); International Standards Organisation (ISO): Geneva, Switzerland, 2008.

2. Yayla, P. Rapid Crack Propagation in Polyethylene Gas Pipes. Ph.D. Thesis, Imperial College of Science, Technology and Medicine, London, UK, January 1991.

3. Argyrakis, C. Models for designing pipe-grade polyethylenes to resist rapid crack propagation, Ph.D. Thesis, Imperial College London, London, UK, March 2010.

4. Krishnaswamy, R.K.; Leevers, P.S.; Lamborn, M.J.; Refister, D.F.; Sukhadia, A.M. Rapid Crack Propagation (RCP) Failures in HDPE Pipes: Structure-Property Investigations. Polym. Eng. Sci. 2005, 10, 3152-3156. [CrossRef]

5. Perkins, W.G. Polymer toughness and impact resistance. Polym. Eng. Sci. 1999, 39, 2445-2460. [CrossRef]

6. Walker, I.; Collyer, A.A. Rubber toughening mechanisms in polymeric materials. In Rubber Toughened Engineering Plastics; Collyer, A.A., Ed.; Springer: The Netherlands, Dordrecht, 1994; pp. 29-56. [CrossRef]

7. Fond, C.; Schirrer, R. Influence of crack speed on fracture energy in amorphous and rubber toughened amorphous polymers. Plast. Rubber Compos. 2001, 30, 116-124. [CrossRef]

8. Fond, C.; Schirrer, R. Dynamic fracture surface energy values and branching instabilities during rapid crack propagation in rubber toughened PMMA. Comptes Rendus de l'Académie des Sciences-Series IIB-Mechanics 2001, 329, 195-200. [CrossRef]

9. Kopp, J.-B.; Schmittbuhl, J.; Noel, O.; Lin, J.; Fond, C. Fluctuations of the dynamic fracture energy values related to the amount of created fracture surface. Eng. Fract. Mech. 2014, 126, 178-189. [CrossRef]

10. Kopp, J.-B.; Fond, C.; Hochstetter, G. Rapid crack propagation in PA11: An application to pipe structure. Eng. Fract. Mech. 2018, 202, 445-457. [CrossRef]

11. Siviour, C.R.; Jordan, J.L. High Strain Rate Mechanics of Polymers: A Review. J. Dyn. Behav. Mater. 2016, 2, 15-32. [CrossRef]

12. Leevers, P.S.; Godart, M.-A. Adiabatic decohesion in a thermoplastic craze thickening at constant or increasing rate. J. Mech. Phys. Solids 2008, 56, 2149-2170. [CrossRef] 
13. Buchar, J. The Effect of Strain Rate Sensitivity on Crack Initiation under Dynamic Loading, in Macro- and Micro-Mechanics of High Velocity Deformation and Fracture. In IUTAM Symposium on MMMHVDF Tokyo, Japan, 12-15 August 1985; Kawata, K., Shioiri, J., Eds.; Springer: Berlin/Heidelberg, Germany, 1987; pp. 231-241.

14. Aboushelib, M.N.; de Jager, N.; Kleverlaan, C.J.; Feilzer, A.J. The influence of pigments on the slow crack growth in dental zirconia. Dent. Mater. 2012, 28, 410-415. [CrossRef]

15. Lodeiro, M.J.; Tomlins, P.E.; Pearce, A. The Influence of Pigments on the Mechanical Properties of High Density Polythylene (HDPE); NPL Report; NPL: Teddington, UK, 2000; CMMT(A)258.

16. Janostik, V.; Senkerik, V. Effect of Pigment Concentration on Mechanical Properties of Polycarbonate. MATEC Web Conf. 2017, 125, 2052. [CrossRef]

17. Kanu, R.; Chesebrough, M.; Spotts, T. The effects of some organic and inorganic pigments on the tensile and impact properties of injection-molded polypropylene. J. Mod. Eng. 2001, 2, 1.

18. Hull, D. Fractography: Observing, Measuring and Interpreting Fracture Surface Topography; Cambridge University Press: Cambridge, UK, 1999.

19. Moreno, L.; Leevers, P. Effect of axial surface scores on rapid crack propagation in polyethylene pipe. Plast. Rubber Compos. 2004, 33, 149-154. [CrossRef]

20. González-Velázquez, J.L. Fractography and Failure Analysis; Springer International Publishing: Cham, 2018.

21. Hayes, M.D.; Shah, A.R.; Edwards, D.B. Fractography in Failure Analysis of Polymers; William Andrew an imprint of Elsevier: Kidlington, Oxford, UK, 2015.

22. Donald, A.M.; Kramer, E.J. The competition between shear deformation and crazing in glassy polymers. J. Mater. Sci. 1982, 17, 1871-1879. [CrossRef]

23. Donald, A.M. The effect of temperature on crazing mechanisms in polystyrene. J. Mater. Sci. 1985, 20, 2630-2638. [CrossRef]

24. Plummer, C.J.G.; Kausch, H.H. Semicrystalline Polymers: Fracture Properties. In Reference Module in Materials Science and Materials Engineering; Elsevier: Amsterdam, The Netherlands, 2016.

25. Deblieck, R.A.; van Beek, D.; Remerie, K.; Ward, I.M. Failure mechanisms in polyolefines: The role of crazing, shear yielding and the entanglement network. Polymer 2011, 52, 2979-2990. [CrossRef]

26. Brown, N. A fundamental theory for slow crack growth in polyethylene. Polymer 1995, 36, 543-548. [CrossRef]

27. Pinter, G. Rißwachstumsverhalten von PE-HD unter statischer Belastung, Ph.D. Thesis, University of Leoben, Leoben, Austria, 1999.

28. Arbeiter, F.; Schrittesser, B.; Frank, A.; Berer, M.; Pinter, G. Cyclic tests on cracked round bars as a quick tool to assess the long term behaviour of thermoplastics and elastomers. Polym. Test. 2015, 45, 83-92. [CrossRef]

29. Frank, A.; Arbeiter, F.J.; Berger, I.J.; Hutař, P.; Náhlík, L.; Pinter, G. Fracture Mechanics Lifetime Prediction of Polyethylene Pipes. J. Pipeline Syst. Eng. Pr. 2019, 10, 04018030. [CrossRef]

30. Leevers, P.S. Impact and dynamic fracture of tough polymers by thermal decohesion in a Dugdale zone. Int. J. Fract. 1995, 73, 109-127. [CrossRef]

31. Leevers, P. Modelling Impact Fracture and RCP Resistance of Thermoplastics from Cohesive Properties. In Proceedings of the Society of Plastics Engineers 2004-Proceedings ANTEC, Chicago, IL, USA, 16-20 May 2004.

32. Leevers, P.; Morgan, R. Impact fracture of polyethylene: A non-linear-elastic thermal decohesion model. Eng. Fract. Mech. 1995, 52, 999-1014. [CrossRef]

33. Narayan, R.; Tandaiya, P.; Narasimhan, R.; Ramamurty, U. Wallner lines, crack velocity and mechanisms of crack nucleation and growth in a brittle bulk metallic glass. Acta Mater. 2014, 80, 407-420. [CrossRef]

34. Leevers, P.S.; (Former Researcher at Department of Mechanical Engineering at Imperial College London, London, UK); Messiha, M.; (Researcher at Polymer Competence Center Leoben GmbH, Leoben, Austria). Personal communication, 2020. 